\title{
Doctoral Peer Writing Groups as a Means of Promoting Well-Being
}

\author{
Sara Doody, Maggie McDonnell, Erin Reid, and Sarah C. Marshall
}

\begin{abstract}
This collaborative autoethnography explores how a doctoral peer writing group (PWG) has become an important means of fostering well-being among the authors, who are four doctoral scholars. Focusing on how writing in doctoral education can act as a barrier to well-being, defined as feeling part of a community, feeling balanced, and feeling motivated by forward momentum, each author shares her particular experiences with writing and how the PWG has contributed to her well-being. Based on the authors' narratives, the article also suggests how PWGs may be useful in promoting well-being across several levels of education.
\end{abstract}

\section{Doctoral Peer Writing Groups as a Means of Promoting Well-Being}

Mental health and overall well-being are becoming key factors for university student success, with healthy campus initiatives on the rise in universities and colleges across Canada (Okanagan Charter, 2015). With full-time doctoral enrollment in Canada increasing 13 percent from 2009 to 2013 (Looker, 2016), success in doctoral education is a particularly timely topic. A 2013 report from McGill's Counselling and Mental Health Services highlighted concerns about graduate student mental health and well-being, especially in regard to the rising population of graduate students generally and doctoral scholars ${ }^{1}$ specifically. Recommendations from this report include improvements of mental health support services to address problems in the domains of mental health and well-being (Di Genova \& Romano, 2014). Increasingly, doctoral well-being is affected by growing institutional demands and expectations, such as the pressure to quickly complete studies or to publish (Elgar, 2003). Moreover, Castro, Garcia, Cavazos, and Castro (2011) point out how a lack of support or mentorship from doctoral supervisors contributes to doctoral stress and may be an important factor in individuals abandoning their doctoral studies. All these variables play a role in the rates of doctoral attrition, with an estimated 30 to 50 percent of doctoral scholars not completing their studies (e.g., McAlpine \& Norton, 2006). Even of those doctoral scholars that complete their degrees, many report the experience of doctoral studies as being "overwhelming" or "very difficult" (Haynes et al., 2012), with stress and social isolation frequently cited as two key areas of struggle in terms of well-being.

There may be several factors that influence the well-being of doctoral scholars, such as financial strain or geographical distance from loved ones, but one institutional factor that commonly negatively affects the well-being of the doctoral scholar is the actual act and process of writing (e.g., Kamler \& Thomson, 2014). Writing is of central importance to doctoral studies, yet it remains a frequent cause of stress (Aitchison \& Lee, 2006; Paré, 2011), which contributes to doctoral scholars feeling isolated and unwell. 
The aim of this paper is to explore and discuss how a peer writing group (PWG) in the context of doctoral education acts as a unique means of fostering well-being among the authors, who are four doctoral scholars. Although we're all researching different things-Sarah M. is looking at teacher education in physical therapy, Sara D. is writing about doctoral writing, Erin is exploring how religious literacy can be beneficial in adult language learning, and Maggie is looking at development of teacher identity in higher education-we've been writing together for over a year now. When Sara began looking into writing groups, she found a great deal written from the perspective of those who encourage us to form groups, but only one paper written from the perspective of an actual group member (Maher et al., 2008). We were inspired to write and share, in hope that others might benefit from this strategy.

\section{Well-Being}

A growing body of research investigates the relationship between well-being and doctoral scholars (Castro et al., 2011; Haynes et. al, 2012; Lovitts, 2001). Stakeholders include institutional policy-makers seeking to maximize institutional efficiency (Elgar, 2003), mental health practitioners concerned with the rising numbers of doctoral scholars among their clients (Di Genova \& Romano, 2014), and doctoral scholars themselves (Nelson, 2014). The motivations of these different stakeholders may be diverse; nevertheless, these factors underlie the burgeoning interest in the well-being of doctoral scholars.

Although the term "well-being" is used frequently in public discourse, governmental and institutional policies, and scholarly research, there remains a wide variety of applications to its usage (Hird, 2003). Within philosophical discussions of the term, well-being is often understood as "a life filled with wholehearted and successful engagement in worthwhile relationships and activities" (White, 2011, p. 11). While there is no single commonly accepted definition of well-being, reference to well-being, across disciplines, demonstrates that the term encompasses not simply an absence of illness, but rather a state of something akin to happiness or satisfaction with one's life or situation (Felce \& Perry, 1995). For the purposes of this paper, we frame our discussion drawing on Felce and Perry, who state that wellbeing "comprises objective descriptors and subjective evaluations of physical, material, social and emotional wellbeing $[\mathrm{sic}]$, together with the extent of personal development and purposeful activity, all weighted by a set of values" (p. 60). In other words, although it is necessary that one feel satisfied with external criteria of one's life, to truly experience well-being this must be combined with a sense of purpose and meaning in one's life.

Drawing on the above conceptualizations of well-being, we sketched our own personal understanding of what this means to us within the doctoral context (see Figure 1). As reflected in our mind-map, we felt that well-being is multi-faceted, and certain aspects of it are naturally unique to one's particular situation. A feeling of isolation is a common complaint among graduate students, and one that each of us has struggled with in our own academic journeys. For us, a significant aspect of our well-being was feeling part of a community. We also felt that balance between our physical, social, emotional, intellectual, and spiritual selves was a crucial ingredient to our well-being. For all four of us, the many facets of doctoral studies itself can become all-consuming, leading us to neglect certain parts of ourselves, whether they be spiritual, emotional, physical, or social. Three of us are mature returners, with ongoing commitments 
to careers, partners, and children; the addition of our scholarly work to that mix at times makes the task of finding balance feel like a precarious juggling act. Finally, as a group of four doctoral scholars, we agreed that well-being includes the feeling of motivation, and moving forward, making progress in our academic project; something that is a worthwhile endeavour to each of us.

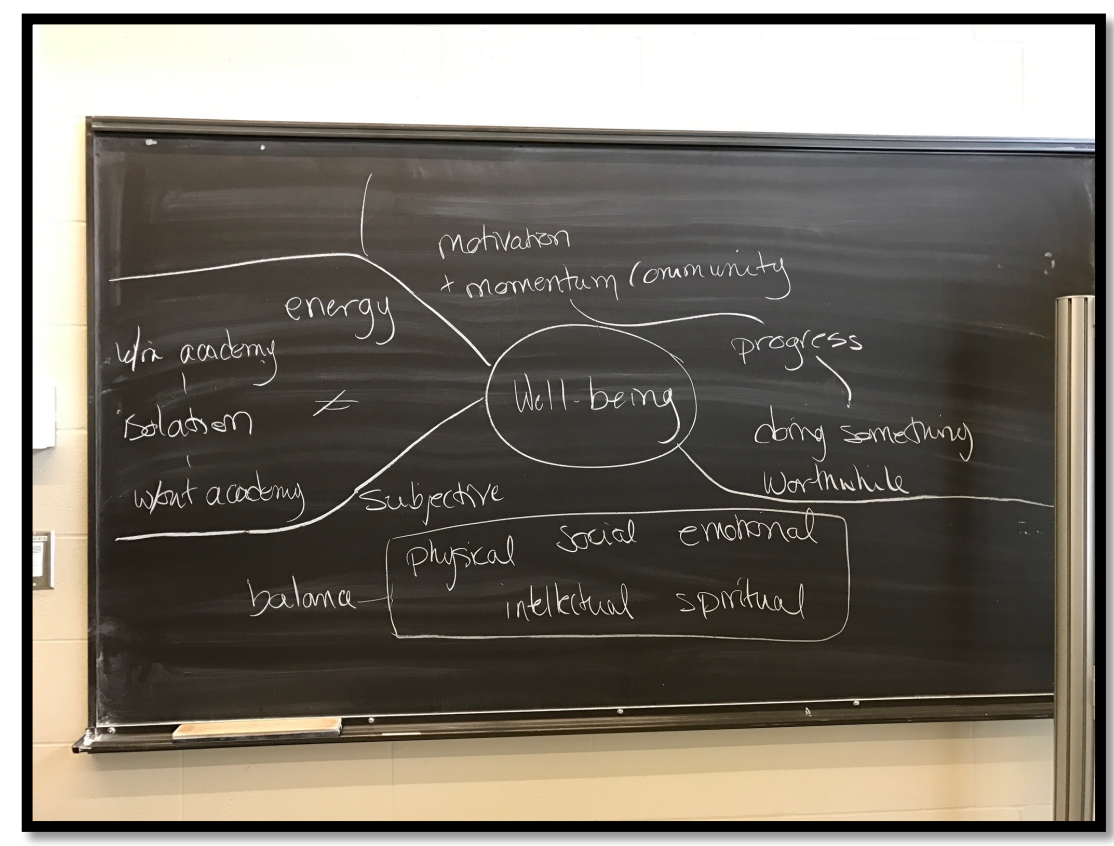

Fig. 1: Mapping our conceptualization of "well-being"

\section{Assumptions About Writing}

As we have mentioned, the act and process of writing can have a negative influence on well-being in doctoral study. Not only is writing commonly perceived as occurring in isolation, it can also feel like a roadblock that prevents us from moving forward, and thus contributes to disrupting balance in our lives. In order to begin to explore our own relationship with writing and well-being, we first needed to probe the idea of what writing is to us, given that there are diverse ways to conceptualize the act and process of writing. A great deal of the stress and frustration so commonly associated with writing stems, we believe, from two pervasive assumptions about what writing is.

One dominant assumption of writing assumes that it exists as a set of skills that can be easily learned and taught; a belief that positions those who are unable to write "well" as skill-deficient (e.g., Aitchison \& Lee, 2006). This orientation towards writing tends to propagate the idea that the "problem" of writing is individualized within the writer herself (Aitchison, Catterall, Ross, \& Burgin, 2012). That is, skill-centered discourses about writing position doctoral scholars as having already learned how to write well, or as being in need of outside assistance (e.g., from writing centers or remedial writing classes). Writing at the doctoral level can become so intimidating for doctoral scholars that they may fear sending their writing 
to their supervisors for feedback and become discouraged and dejected when they see reviews of their work that essentially instruct them to change everything (Starke-Meyerring, 2011).

A second common assumption about writing is that it must be done in isolation. The act and process of writing itself is largely hidden and even marginalized in graduate education, meaning that writing is often perceived as starting after the real intellectual work has been finished (i.e., after the research has been done), instead of being viewed as a part of the intellectual work itself. Writing remains on the margins of doctoral work and the status quo assumption that writers require isolation and solitude to simply "writeup" their thoughts continues to be internalized by doctoral writers (Kamler \& Thomson, 2014; StarkeMeyerring, 2014). While universities express concern over doctoral writing, further discussions about this concern remain largely neglected (Paré, 2011). It is in part because of these assumptions (that writing is a set of skills performed individually in isolation), doctoral scholars often end up feeling like writing is something that they cannot do, which can have a profound effect on their sense of well-being.

Guided by the thinking of rhetorical genre scholars, we situate our PWG within a markedly different view of writing. For us, writing is not so much a skill as it is a form of situated and social practice. That is, we view the specific kinds of writing that we must produce as typified responses to recognizable and recurrent social situations, or as genres (Miller, 1984/1994; Schryer 1993). Genres are fairly stable kinds of discourse that are produced within particular communities and perform specific kinds of regularized social actions, while also (re)producing the community itself (Freedman \& Medway, 1994). From a genre perspective, writing is not simply a skill that can be easily acquired, but is the embodiment of a precise set of social practices and beliefs that are passed down and reproduced by members of a specific group. The situated and historical nature of genre means that its conventions, or features, that make a particular example of a genre recognizable and acceptable, are often perceived as common sense to experts, yet to learners, these conventions can be shrouded in mystery (Paré, 2002). The "hidden nature" of genre is particularly important when exploring how writing comes to be associated with issues of well-being, because established members of academic communities often believe that what constitutes "good" writing is obvious (Starke-Meyerring, Paré, Sun, \& El-Bezre, 2014). The inability to recognize and produce the genres of a particular community often leaves doctoral scholars feeling as though they cannot write and that they are imposters in academia. Again, this has a powerful impact on all three of the facets of well-being discussed above, with doctoral scholars struggling to learn tacit genre conventions on their own, causing them to lose the balance in their lives, and to lose motivation, feeling as though they have ceased to move forward in their academic journey (e.g., Starke-Meyerring, 2011).

\section{Collaborative Autoethnography}

In the fall of our second year in our doctoral program, we led a discussion with our graduate colleagues on how our PWG was helping us to overcome the struggles of academic life. This paper grew out of that discussion. In retrospect, it seems inevitable that we would want to write together; that is, not just side by side, but on a single, heteroglossic text, our four voices each represented separately and yet together, as a collaborative autoethnography. 
The term autoethnography may imply a solo researcher, but often researchers work together in collaborative autoethnography, defined as "a qualitative research method in which researchers work in community to collect their autobiographical materials and to analyze and interpret their data collectively" (Chang, Ngunjiri, \& Hernandez, 2013, p. 23). Collaborative autoethnography typically begins with "group sharing [and] probing" (p. 23) and subsequent stages of data analysis involve group interpretation, with the final product being an exercise in group writing. Chang and colleagues argue that collaborative autoethnography allows researchers to engage in self-reflection and collective analysis simultaneously. This variation on the concept of autoethnography lends credibility to the research, since the group is involved in a collective exploration; furthermore, collaborative autoethnography offers researchers an even deeper understanding of the self and others, and begins building community from within the research cycle itself (p. 25).

Rather than community arising from the process, for us, the process seems to have arisen from the community. Thus, arguably, Chang et al.'s (2013) unidirectional depiction of the collaborative autoethnographic process can be expanded to include experiences like ours: groups who have been working side by side, becoming a community, recognizing the collective and individual rewards of this group dynamic, and then reflecting on the experience itself. Reflecting on our process revealed to us just how important the PWG has become in terms of our well-being, especially in terms of our writing as doctoral scholars.

\section{PWG, Writing, and Well-Being}

Based on our assumptions of well-being and writing discussed above and using a collaborative autoethnography approach, below we reflect on how our PWG has provided a unique space to foster well-being in the doctoral context through its collaborative nature, the balance it provides to our lives, and through group motivation.

\section{Our Peer Writing Group}

The PWG that we are involved in was created as a consequence of the four of us bemoaning how hard it was to actually sit down and write during the first year of our doctoral journey. We were fortunate to have a doctoral seminar leader in our first year together who almost casually mentioned getting together to write, and a mutual gap in our schedules that made it easy and natural to do so. The group began when one of us sent out a fairly informal invitation to write, which was emailed to a larger cohort of 17 students, and has evolved into a very important part of our doctoral process. At the outset, a common complaint amongst the four of us was that we felt stalled in our work; we had lost our momentum, we couldn't write, we weren't getting where we wanted, and we were frustrated and irritated by this. We decided we would meet once every two weeks to write, and in the intervals between, share our frustrations about what we were doing. Therefore, initially, the group was organized in a "shut-up-andwrite" (SUAW) format in order to help us feel as though we were getting writing done. Typically, we use 
the Pomodoro method, so in our two-hour sessions, we write in 25-minute sessions, taking a short break to chat, or share bits of our writing.

In the beginning of the second year of our doctoral journey, the initial SUAW format evolved into review sessions alternating with writing sessions. This seemed a natural progression for a few reasons. We started the PWG as virtual strangers, so the initial SUAW sessions were low-risk for us all. However, as we began getting to know each other better over the summer between first and second year, we started meeting weekly, sometimes to write, but increasingly to review. Our group now tries to meet once a week-many groups meet less frequently, but we're using the weekly appointment as a way of keeping ourselves connected to the habit of public writing. Last fall, as we all worked on grant applications and candidacy papers, we decided to dedicate one session each month to a share-and-respond session, wherein we exchange computers and comment in writing on each other's work. We discuss our comments before we end the session, and we each leave with at least two other people's feedback recorded in our text, for reflection and reference.

In our feedback, we aim to ask questions that encourage the writer to think critically about what she is writing and why, not to criticize structure and ideas. While the members of our group have different backgrounds and experiences with writing and writing groups, and are working on different research topics, all of us have come to look forward to our weekly meetings for the support and motivation they provide, in both our academic careers and even in our personal lives.

Our main goal is to illustrate how participating in a doctoral PWG has been an integral part of maintaining our well-being as doctoral scholars. We have chosen to present individual commentaries about how each of our specific experiences speaks to fostering well-being according to our three-part definition introduced above. In addition, following the example of groups like Maher and colleagues (2008), we provide a collective commentary on how all of the individual narratives speak to the larger issue of doctoral well-being in relation to writing.

\section{Collaboration}

[Erin] It took me a long time to understand how collaboration could lead to well-being in my graduate studies. I think I was, perhaps like many, resistant to the idea that writing and research could be done collaboratively. Throughout most of my university education, I was under the impression that good writing could only come out of some kind of solitary, hermit-like process. I was also somehow convinced that this solitary writing must be accompanied by intense personal stress-it certainly seemed to be intensely stressful for my fellow students. Like so many of my peers, I struggled to see myself as a legitimate writer/scholar, frequently suffering from what I would eventually name as CSD (crippling selfdoubt). This CSD might be mentioned in passing as a self-deprecating joke, but I took it as a natural, though unfortunately painful, part of the writing process. Looking back on my earlier university experiences with writing, I can't help but wish I had been more aware of the immeasurable benefits in sharing one's work with a writing group, and the fruitfulness of collaborative writing. 
[Sarah] When I first started this PhD journey, I felt like a fish out of water. Having spent more than half my life in science and quantitative settings, to be immersed in the social sciences was a big change, to say the least. One of my classmates coined CSD, but I knew that feeling as the "Imposter Syndrome," that is to say I felt that soon, maybe very soon, someone would find out that I was simply an imposter and really didn't know what I was doing, what I was writing about or really, what was going on at all. When the idea of writing in a group surfaced, I thought, "That's crazy! How can you write with people around?" And then I tried writing on my own. So many words that just would not come. When we started our SUAW sessions, I saw the light and realized the value of recognizing the commonalities of our disparate situations: all four of us were trying to produce thoughts, ideas, reflections and text, and for me the best way to do that is not in fact alone in a hermit's shack, but right beside someone else who also was madly typing away.

[Maggie] It took me a while to start my doctoral journey. I already had two Masters degrees, and a permanent teaching position in a college system that guarantees my employment and pension. In fact, rather than get back into academia, I enrolled in fitness instructor courses, and became a certified yoga instructor. While the lure of academia was there, I was also a little gun-shy after the isolating experience of my second Masters. When I did find my way to our program, it felt like this PWG was exactly what I needed-even once our course work was done, we would have our commitment to each other to continue, as a community of scholars. As Sarah said, my initial reaction to actually writing side by side was skeptical, and the idea of writing collaboratively was frankly inconceivable. But the idea of maintaining contact, and of exchanging feedback, got me over those uncertainties.

[Sara] The initial "shut-up-and-write" sessions were useful for getting us to write, but were perhaps more important for what happened between the writing. The most useful parts of our meetings, for me, were really the interactions between writing intervals. I think one of the most important things that developed from this was that we built a community through collaborating with each other, listening to what everyone was working on, getting a sense of how they thought, but also getting a sense of my own thinking when I had to explain my work. The overtly social nature of the group was huge, especially because prior to this, I felt really detached from any kind of collegial community. This really helped me feel less lonely and isolated as a doctoral scholar.

Group commentary. A common thread throughout our individual reflections is how writing alongside others has become a particularly important way of maintaining our well-being during the doctoral writing process. As we have pointed out, writing in doctoral contexts is often done alone, both in a literal and figurative sense (Kamler \& Thomson, 2014). Most of us have had these experiences in the past, where writing meant being isolated and locked away from the world in a physical sense, but also in the sense that we really didn't have anyone to write for. Without the understanding of writing as social, as being directed towards a larger community of our colleagues, the feelings of isolation we experienced only increased. Working in this writing group, however, has made this social nature of writing more visible through the kinds of collaboration we have undertaken. As Sara and Maggie point out, sharing the difficulties we were facing with our writing and getting suggestions from our colleagues enabled us to begin seeing writing as much more collaborative and social. 


\section{Balance}

[Erin] Being a doctoral PWG member has allowed me to renegotiate my relationship with the writing process and to highlight the importance of balance in graduate studies. The struggle I experienced with writing in my undergraduate studies intensified dramatically when I found myself in graduate school as a Master's student in religious studies where the long-standing trope of the solitary, struggling, and hopefully brilliant writer was in full force. Though graduate students shared a large office, so inevitably ended up occasionally writing at the same time, our writing was never shared, only our anxieties and self-doubts. Moreover, there seemed to me to be a direct correlation between the most stressed out student and the most brilliant-writing the bulk of my master's thesis in three painful weeks was something of a badge of honour for me. However, this writing experience was so intensely horrible that it literally led to me being unable to move my head for weeks and it took me over a year of physiotherapy sessions to heal its physical effects. This extreme experience points to a complete lack of balance in my life at the time: I was consumed with writing and made no attempt to nurture any other part of myself, be it physical, social, or spiritual.

[Sarah] Hearing the trials and tribulations of the other members of this PWG has helped normalize my own feelings and experiences. I find it easier to sit down and write when it is time to write, and stop and go for a walk or a swim when it is time for that. We support each other in our various stages of the journey, and we don't judge what or when or why. Three of my departmental colleagues have begun their graduate degrees recently and I've mentioned the PWG and some of the lessons I've learned and continue to learn, to them. It's almost like the balance I'm getting from the PWG has a ripple effect and is affecting others in our inner and outer circles.

Group commentary. The PWG has shown each of us that we are not alone in struggling to find balance in the doctoral process. As Erin and Sarah point out, writing in graduate studies has the potential to become all-consuming and can lead to burn-out and other physical health issues. The fear of reliving past writing traumas was one impetus for continuing to meet after our first session together. Forming the writing group allowed us to create a social space for our writing and has become like a life preserver, preventing us from drowning in our individual writing. In addition, the social nature of the writing has allowed us to engage in one of Felce and Perry's (1995) components of well-being that we drew on; namely, personal development alongside others. This personal development is an important factor in maintaining balance in our lives. This balance, in which we are neither completely consumed by our doctoral work, nor completely distracted from it, allows us to maintain our momentum.

\section{Motivation and Momentum}

[Maggie] I think for me, the forward momentum is the most important facet of the PWG. When I was working on my MEd, I found myself discouraged to the point of quitting because one college with which I was working delayed my process so much that by the time I finally got their green light, I had lost my steam. One of the fears I had about embarking on the doctoral journey was that I would get to the research and writing leg and just quit. The PWG, through our regular meetings and supportive community, gives 
me that sense of moving forward, and personally, a sense that I am accountable. Someone will notice if I stop, and, knowing this group, they'll throw me a towrope.

[Sara] I also think that an important part of this group has been how motivating it is: it makes me get things done. After review sessions and hearing what people think about my writing and asking me questions about what I am doing, I feel really motivated to get to work. Working with a PWG and talking through the written work always ends up with both really actionable feedback (how do you define this?) as well as new ideas that are built in the discussion through questions (is this what you mean? or this is your main point and this is how things are supposed to hang together, right?).

[Sarah] The deadline of biweekly and then weekly meetings to write and share our writing has been of tremendous help to me. I am fairly organized, and in general work to deadlines, but at the start of the first semester of my PhD, trying to "fit in some writing" was useless. I got very little done on my own, because writing is difficult, especially perhaps for me coming from a science background. I especially loved it when we shared our writing; I got to see how the others in the PWG expressed themselves, how they framed their arguments and supported their conclusions. The experience also helped get me used to seeing writing that was more expansive and eloquent than what I had seen in typical science journals.

[Erin] Sharing my writing with my peers has been a real revelation to me and an incredible motivating force. As I've previously mentioned, I have spent large amounts of time during my academic studies immersed in self-doubt and very reluctant to share my work with anyone. This has been a problem for me my whole life, and I recognize that my self-doubt has often held me back. As I began to share my work, I developed skills in critical reading, editing, and giving and receiving feedback, which in turn have led to a growing sense of confidence in my academic self. Supported by the weekly meetings with my peers in the writing group, this emerging confidence in turn motivates me to continue on my doctoral journey.

Group commentary. One common thread weaving throughout our discussion on how the writing group contributes to our well-being through motivation is the support system this group has developed. As discussed above, one of the barriers to doctoral well-being is a lack of community and peer support through the doctoral process. Our PWG allows us to experience ourselves as members of a writing group. This in turn facilitates identifying ourselves as part of a larger peer community and scholarly community (Maher et al., 2008). We still experience the pressures and realities of doctoral studies, but through our supportive weekly PWG meetings, we have developed an increased ability to situate ourselves as researchers and as legitimate academic writers who are actively navigating the PhD journey, keeping well in mind, body, and spirit. 


\section{Reflecting on the Process}

As described above, we see our well-being as doctoral scholars as comprising community, balance, motivation, and momentum. In our individual commentaries, we have shared how the PWG has become an integral and essential facet of our individual and collective well-being as doctoral scholars. Perhaps most importantly, writing, for us, now isn't something to be intimidated by. We have recognized and rejected the dominant assumptions surrounding academic writing; we work with writing so much that we have developed a way of talking about it together, which has created a unique space that fosters community, collaboration, balance, motivation, and momentum. This community space, as Sara discusses above, supports our practice as writers. Viewing writing as a situated practice has been particularly helpful in the peer review process, which has taught us to seek out and address constructive feedback on our work. The support we receive through our PWG develops our feelings of confidence in various genres of academic writing. As Sarah pointed out in her discussion of "imposter syndrome," the PWG experience also gives us a greater sense of our legitimacy as doctoral scholars. We have felt that situating our PWG within a rhetorical perspective helps us to renegotiate how we experience writing, because instead of struggling in isolation as Erin did, we are working and writing together. We are not in danger of losing balance in our lives; or stagnating in our process, like Maggie did, because we have each other to keep us afloat.

There are myriad resources, online and on some campuses, to help scholars and students set up writing groups. We suggest that departments would be wise to recognize the struggles of student writers, and to more actively encourage PWGs, particularly among graduate and doctoral scholars. We feel strongly that other doctoral scholars can benefit from PWGs. In fact, we would argue that our experience demonstrates how PWGs are an effective pedagogical tool, as well as a space that fosters well-being.

\section{Note}

1. While individuals pursuing a doctorate may have specific titles based on their progression in their program (i.e., doctoral student, doctoral candidate), here we use the term "doctoral scholars" to refer to all members of the doctoral population. 


\section{References}

Aitchison, C., \& Lee, A. (2006). Research writing: Problems and pedagogies. Teaching in Higher Education, 11(3), 265-278. doi:10.1080/13562510600680574

Aitchison, C., Catterall, J., Ross, P., \& Burgin, S. (2012). 'Tough love and tears': Learning doctoral writing in the sciences. Higher Education Research and Development, 31(4), 435-447. doi:10.1080/07294360.2011.559195

Castro, V., Garcia, E. E., Cavazos, J., Jr., \& Castro, A. Y. (2011). The road to doctoral success and beyond. International Journal of Doctoral Studies, 6, 51-77.

Chang, H., Ngunjiri, F. W., \& Hernandez, K-A. C. (2013). Collaborative autoethnography. Walnut Creek, CA: Left Coast Press.

Di Genova, L., \& Romano, V. (2014). Student psychological well-being at McGill University: A report of findings from the Counselling and Mental Health Benchmark Study. Retrieved from https://www.mcgill.ca/counselling/files/counselling/student_psychological_well-

being_at_mcgill_december_2014_final_3.pdf

Elgar, F. (2003). PhD completion in Canadian universities. Halifax: University of Dalhousie.

Felce, D., \& Perry, J. (1995). Quality of life: its definition and measurement. Research in Developmental Disabilities, 16(1), 51-74. doi:10.1016/0891-4222(94)00028-8

Freedman, A., \& Medway, P. (1994). Locating genre studies: Antecedents and prospects. In A. Freedman, \& P. Medway (Eds.), Genre and the new rhetoric (pp. 2-18). Bristol, PA: Taylor \& Francis.

Haynes, C., Bulosan, M., Citty, J., Grant-Harris, M., Hudson, J. C., \& Koro-Ljungberg, M. (2012). My world is not my doctoral program . . . or is it? Female students' perceptions of well-being. International Journal of Doctoral Studies, 7, 1-17.

Hird, S. (2003). What is wellbeing? A brief review of current literature and concepts. NHS Health Scotland: Glasgow.

Kamler, B., \& Thomson, P. (2014). Helping doctoral students write (2nd ed.). New York: Routledge.

Looker, D. E. (2016). 42nd statistical report Canadian Association of Graduate Studies, 2016. Retrieved from http://www.cags.ca/documents/stats/42ndSTATISTICALREPORTFINAL.ENG.pdf

Lovitts, B. E. (2001). Leaving the ivory tower: The causes and consequences of departure from doctoral study. Lanham, MD: Rowman \& Littlefield.

Maher, D., Seaton, L., McMullen, C., Fitzgerald, T., Otsuji, E., \& Lee, A. (2008). 'Becoming and being writers': The experiences of doctoral students in writing groups. Studies in Continuing Education, 30(3), 263-275. doi:10.1080/01580370802439870

McAlpine, L. \& Norton, J. (2006). Reframing our approach to doctoral programs: An integrative framework for action and research. Higher Education Research \& Development, 25(1), 3-17. doi:10.1080/07294360500453012 
Miller, C. R. (1994). Genre as social action. In Freedman, A. \& Medway, P. (Eds.), Genre and the new rhetoric (pp. 20-36). Bristol, PA: Taylor \& Francis. (Reprinted from Quarterly Journal of Speech, 1984, 70, pp. 151-67).

Nelson, K. (2014). Academic progress in doctoral students: Levels of hope, subjective well-being, and stress (Doctoral dissertation). Retrieved from ProQuest dissertations and theses. (1620850337)

Okanagan Charter. (2015). Proceedings from International Conference on Health Promoting Universities and Colleges. Kelowna, British Columbia, Canada.

Paré, A. (2002). Genre and identity: Individuals, institutions, and ideology. In R. Coe, L. Lingard, \& T. Teslenko (Eds.), The rhetoric and ideology of genre (pp. 57-71). Cresskill, NJ: Hampton Press.

Paré, A. (2011). Speaking of writing: Supervisory feedback and the dissertation. In L. McAlpine, \& C. Amundsen (Eds.), Doctoral education: Research-based strategies for doctoral students, supervisors and administrators (pp. 59-73). New York: Springer.

Schryer, C. F. (1993). Records as genres. Written communication, 10(2), 200-234. doi:10.1177/0741088393010002003

Starke-Meyerring, D. (2011). The paradox of writing in doctoral education: Student experiences. In L. McAlpine \& C. Amundsen (Eds.), Doctoral education: Research-based strategies for doctoral students, supervisors and administrators (pp. 74-95). New York: Springer.

Starke-Meyerring, D. (2014). Writing groups as critical spaces for engaging normalized institutional cultures of writing in doctoral education. In C. Aitchison \& C. Guerin (Eds.), Writing groups for doctoral education and beyond: Innovations in theory and practice (pp. 65-81). New York: Routledge.

Starke-Meyerring, D., Paré, A., Sun, K. Y., \& El-Bezre, N. (2014). Probing normalized discourses about writing: The case of the doctoral thesis. Journal of Academic Language and Learning, 8(2), A13-A27.

White, J. (2011). What does it matter to be well-educated? Think, 28(10), 9-16. doi:10.1017/S1477175611000078 


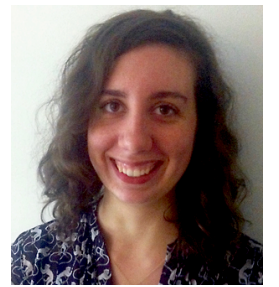

Sara Doody is a doctoral student in the Department of Integrated Studies in Education at McGill University. She is interested in writing in higher education, particularly in natural and physical science fields. Her current doctoral research explores the relationship between doctoral writing and identity in interdisciplinary science programs.

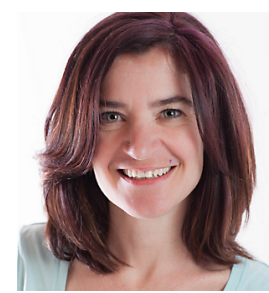

Maggie McDonnell is a doctoral candidate and course lecturer in McGill University's Department of Integrated Studies in Education. She also teaches English Literature and Liberal Arts at Vanier College, and is a part-time yoga instructor. Her doctoral research focuses on personal and professional identity in higher education teachers, and the relationship between identity and approaches to assessment. Other research interests include communities of practice, the role of failure in the learning process, and development of academic identity.

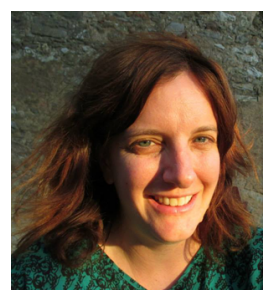

Erin Reid is pursuing doctoral studies under the guidance of Dr. Kevin McDonough in the Department of Integrated Studies in Education at McGill, investigating the role of religious literacy in second language pedagogy in higher education. Her academic background in second language education and religious studies, along with her eight years' experience as an educator in the McGill's Department of Language and Intercultural Communication, have led to her current interdisciplinary research. She was the 2015 recipient of the award for Distinguished Teaching in McGill's School of Continuing Studies.

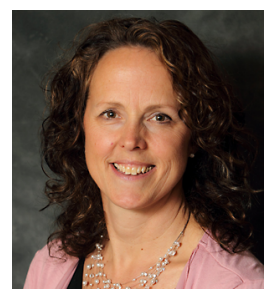

Sarah C. Marshall has been a physiotherapist for over 30 years. At present, she has a university appointment in the PT department at McGill, and one of her tasks is educating Master-level students in the PT program. Sarah's curiosity about how to teach better has led her to explore curriculum design and pedagogical studies in the Education Department, where she is now a PhD student. Sarah is studying under Dr. Lynn Butler-Kisber in the Department of Integrated Studies in Education (DISE). 